\title{
Oncogene SRC
}

National Cancer Institute

\section{Source}

National Cancer Institute. Oncogene SRC. NCI Thesaurus. Code C17398.

A retroviral DNA or mutated host gene that encodes a hyperactive form of the protooncogene tyrosine-protein kinase Src protein. This oncogene is involved in tyrosine phosphorylation and cellular transformation. 